\title{
Slowed Tongue Motion
}

National Cancer Institute

\section{Source}

National Cancer Institute. Slowed Tongue Motion. NCI Thesaurus. Code C127205.

A finding of slowed tongue motion during swallowing. 